\title{
Medicolegal Causation Investigation of Bacterial Endocarditis Associated with an Oral Surgery Practice Using the INFERENCE Approach
}

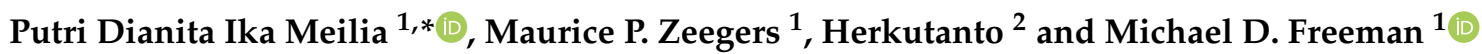 \\ 1 Care and Public Health Research Institute (CAPHRI), Maastricht University Medical Center+, \\ Universiteitssingel 40, 6229 ER Maastricht, The Netherlands; m.zeegers@maastrichtuniversity.nl (M.P.Z.); \\ m.freeman@maastrichtuniversity.nl (M.D.F.) \\ 2 Department of Forensic Medicine and Medicolegal Studies, Faculty of Medicine, University of Indonesia, \\ Jl. Salemba Raya No. 4, Salemba, Jakarta Pusat 10430, Indonesia; herkutanto@yahoo.co.id \\ * Correspondence: p.meilia@maastrichtuniversity.nl; Tel.: +62-812-9025-2577
}

check for

updates

Citation: Meilia, P.D.I.; Zeegers, M.P.; H.; Freeman, M.D. Medicolegal Causation Investigation of Bacterial Endocarditis Associated with an Oral Surgery Practice Using the INFERENCE Approach. Int. J. Environ. Res. Public Health 2021, 18, 7530. https://doi.org/10.3390/ ijerph18147530

Academic Editor: Paul B. Tchounwou

Received: 24 May 2021

Accepted: 5 July 2021

Published: 15 July 2021

Publisher's Note: MDPI stays neutral with regard to jurisdictional claims in published maps and institutional affiliations.

Copyright: (c) 2021 by the authors. Licensee MDPI, Basel, Switzerland. This article is an open access article distributed under the terms and conditions of the Creative Commons Attribution (CC BY) license (https:// creativecommons.org/licenses/by/ $4.0 /)$.

\begin{abstract}
Investigating causation is a primary goal in forensic/legal medicine, aiming to establish the connection between an unlawful/negligent act and an adverse outcome. In malpractice litigation involving a healthcare-associated infection due to a failure of infection prevention and control practices, the medicolegal causal analysis needs to quantify the individual causal probabilities to meet the evidentiary requirements of the court. In this paper, we present the investigation of the most probable cause of bacterial endocarditis in a patient who underwent an invasive procedure at a dental/oral surgical practice where an outbreak of bacterial endocarditis had already been identified by the state Department of Health. We assessed the probability that the patient's endocarditis was part of the outbreak versus that it was an unrelated sporadic infection using the INFERENCE (Integration of Forensic Epidemiology and the Rigorous Evaluation of Causation Elements) approach to medicolegal causation analysis. This paper describes the step-by-step application of the INFERENCE approach to demonstrate its utility in quantifying the probability of causation. The use of INFERENCE provides the court with an evidence-based, transparent, and reliable guide to determine liability, causation, and damages.
\end{abstract}

Keywords: INFERENCE approach; malpractice litigation; medicolegal causal analysis; quantification of causation; bacterial endocarditis; infection prevention and control practices

\section{Introduction}

Causation is broadly defined as the cause-and-effect relationship between an action and an outcome. The investigation of causation is a primary goal in forensic/legal medicine, a multifaceted discipline that is a hybrid of medicine, law, and public health [1,2]. Medicolegal analysis of causation is necessary in legal actions involving injury, disease, and death to establish the nexus between an unlawful or negligent act and a subsequent adverse outcome. Depending on the circumstances, the complexity of causal evaluations ranges widely, with many assessments of simple cases requiring only the application of scientific common sense and professional intuition [3]. In more complex cases, however, a more in-depth causal investigation is warranted. A representative example is a medical negligence (i.e., malpractice) action involving a disease outbreak that has allegedly resulted from a faulty medical procedure or practice. There are many facets to such an investigation, and a systematic approach that maximizes the transparency of methods is ideal.

Healthcare-associated infections (HAIs) arise in several scenarios [3,4]. Most infections reflect the largely unpreventable background rate of HAIs resulting from the abundance of pathogens found in healthcare settings. A smaller number of infections are preventable and sporadic, such as peritonitis due to an overlooked bowel injury during surgery. An 
even smaller group of preventable infections occurs in clusters or outbreaks and results from the repeated failure of infection prevention and control (IPAC) practices.

HAIs can occur in practically every healthcare setting, including dental and oral surgical practices [5-7]. A particularly serious HAI associated with some dental procedures is bacterial endocarditis (BE). In dental practice, there is a well-recognized risk of bacteremia by oral commensal microorganisms via disruption of the oral mucosa or gums [8-10]. Bacteremia is, in turn, associated with potentially severe and life-threatening complications, including BE, an infection of the lining of the heart, including the heart valves [11,12].

An infectious disease outbreak is usually defined as an increase of infections compared to the expected number during a specific time and in a certain place [13,14]. If, in a healthcare setting, it can be demonstrated that the increase is not due to known external factors, then it is reasonable to infer that a systematic failure of IPAC is the most logical explanation for the infections.

Initial investigations of HAI outbreaks are ordinarily conducted by public health agencies with the legal authority to inspect premises and practices. When a subsequent legal action for an individual personal injury is associated with an HAI outbreak, the methods for medicolegal analysis will likely incorporate the public health agency findings and methods but also require unique additional steps to quantify the individual/specific causal probabilities for the judge or jury to meet the evidentiary requirements of the court [15].

This paper presents the investigation of the most probable cause of $\mathrm{BE}$ in a patient who underwent an invasive procedure at a dental/oral surgical practice where an outbreak of $\mathrm{BE}$ had already been identified through a public health investigation by the state Department of Health [16]. The purpose of the medicolegal investigation was to assess the probability that the patient's BE was related to the dental procedure (i.e., that the patient's infection was part of the outbreak) versus the probability that it was an unrelated sporadic infection. The INFERENCE (Integration of Forensic Epidemiology and the Rigorous Evaluation of Causation Elements) approach to medicolegal causation analysis was used to organize the evidence and quantify the causal probabilities for presentation as expert opinion in a personal injury civil action brought by the patient [17].

\section{Materials and Methods}

\subsection{Case Description}

The patient, "Mrs. D", was a 69-year-old female in generally good health who underwent a procedure at "Dr. X's" dental and oral surgery practice.

\subsection{Relevant Medical History}

A chronology of Mrs. D's relevant medical history is detailed in Table 1.

\subsection{Public Health Investigation Findings}

An investigative team from the state Department of Health conducted two unannounced inspections and environmental assessments of the clinic [16]. The investigation revealed that Dr. X performed all procedures at the practice with at least one assistant. The initial assessment identified multiple breaches of IPAC practices from the Centers for Disease Control and Prevention (CDC)'s Guidelines for Infection Control in Dental Healthcare Settings [6].

A total of 3756 unique patients were treated in the clinic during 2013 and 2014. Patients of the practice who were evaluated in an emergency department or hospitalized from 1 January 2013 through 30 June 2015 were identified. The diagnostic codes associated with their emergency department visit or hospitalization were reviewed. The public health investigation identified 14 confirmed cases/patients with E. faecalis endocarditis [16]. All patients had surgery at the same clinic performed by Dr. X. 
Table 1. Relevant medical history timeline for Mrs. D. Signs and symptoms associated with bacterial endocarditis (BE) are underlined.

\begin{tabular}{|c|c|}
\hline Time (Relative to Procedure) & Evidence \\
\hline Day 0 & $\begin{array}{l}\text { Mrs. D underwent a lumpectomy on the lateral tongue and side of the cheek performed by Dr. } \\
X \text { under IV sedation. Post-procedure, Dr. X prescribed an antibiotic (azithromycin). }\end{array}$ \\
\hline Day 2 & $\begin{array}{l}\text { Mrs. D noticed the left side of her neck was swollen, and by the following day, she had pain in } \\
\text { her ear and beneath the angle of her left jaw. }\end{array}$ \\
\hline Day 4 & $\begin{array}{l}\text { Mrs. D contacted Dr. X's office with a complaint of a swollen gland and was told to take an } \\
\text { over-the-counter non-steroidal anti-inflammatory drug (NSAID). }\end{array}$ \\
\hline Day 14 & $\begin{array}{l}\text { Mrs. D returned to Dr. } X \text { for follow-up and was advised that the excised mass was benign. The } \\
\text { incision was healing well. Further follow-up was scheduled in } 4 \text { days for the swollen glands, } \\
\text { which Mrs. D canceled as she was feeling better. }\end{array}$ \\
\hline Day 20 & $\begin{array}{l}\text { Mrs. D awoke with a fever and dizziness. She managed the fever with ibuprofen but } \\
\text { continued to feel unwell over the next two weeks. }\end{array}$ \\
\hline Day 49 & $\begin{array}{l}\text { Mrs. D presented to an internal medicine specialist reporting flu-like symptoms and left } \\
\text { shoulder pain. Cardiac auscultation revealed a regular rate and rhythm without a murmur. }\end{array}$ \\
\hline Day 63 & $\begin{array}{l}\text { Mrs. D awoke with severe pain radiating from the left shoulder to the breastbone, with dorsal } \\
\text { muscle spasms. The pain persisted in her lower back and left scapula. }\end{array}$ \\
\hline Day 80 & $\begin{array}{l}\text { Mrs. D began spiking fevers again. She continued to feel unwell, dizzy, and weak, and } \\
\text { developed a productive cough. }\end{array}$ \\
\hline Day 90 & $\begin{array}{l}\text { She revisited the internist who diagnosed acute bronchitis and was prescribed a 10-day course } \\
\text { of levofloxacin } 500 \mathrm{mg} \text {. }\end{array}$ \\
\hline Day 118 & $\begin{array}{l}\text { Mrs. D continued to feel unwell. The internist refilled the levofloxacin and referred Mrs. D for } \\
\text { infectious diseases consult due to continuous fever }\left(39.4^{\circ} \mathrm{C}\right) \text {, sweats, and dizziness. }\end{array}$ \\
\hline Day 128 & $\begin{array}{l}\text { Mrs. D presented to the emergency department with } \\
\text { spiking fevers and an altered mental state. She began urgent workup for fever of unknown } \\
\text { origin including blood and urine cultures, electrocardiography (ECG), and echocardiogram and } \\
\text { commenced empirical vancomycin and ceftriaxone. } \\
\text { She demonstrated signs of edema in both lower extremities. The ECG showed sinus } \\
\text { tachycardia (108 bpm) with frequent premature ventricular contractions. The results of the } \\
\text { blood cultures revealed Gram-positive cocci and E. faecalis. Initial transesophageal } \\
\text { echocardiogram revealed a possibly prolapsed aortic valve, highly suspicious for vegetation. } \\
\text { Thoracic magnetic resonance imaging (MRI) demonstrated cardiomegaly with left atrial } \\
\text { enlargement and small bilateral pleural effusions. }\end{array}$ \\
\hline Day 133 & $\begin{array}{l}\text { Repeat echocardiogram confirmed signs of } \\
\text { aortic valve endocarditis, a large mobile vegetation with likely perforation of aortic leaflets, } \\
\frac{\text { and moderate to severe aortic regurgitation. Mrs. D was diagnosed with acute aortic valve }}{\text { endocarditis with valve perforation resulting in dynamic shortness of breath, likely }} \\
\text { secondary to congestive heart failure. She required urgent surgery. }\end{array}$ \\
\hline
\end{tabular}

Table 2 lists the illness onset versus procedure timing and other key features of the 14 patients. The patients are listed in chronological order by the date of the oral procedure.

\subsection{Legal Allegations}

Mrs. D filed a suit against Dr. X's practice, alleging that she contracted BE because of negligent IPAC violations occurring during her oral surgery. The defense argued that most cases of BE, and infective endocarditis in general, do not occur in dental practices but occur sporadically or are idiopathic $[11,12,18,19]$. Thus, while Mrs. D's BE may have resulted from her exposure to Dr. X's practice, it also could have arisen spontaneously. Therefore, it could not be said that the infection resulted from the exposure to the standard required by the court, which was "on a more probable than not (>50\% probable) basis." 
Table 2. List of age, sex, date of surgery, time between surgery and symptom onset (days), and time between surgery and diagnosis of bacteremia of the cases. Mrs. D is Patient \#13.

\begin{tabular}{cccccc}
\hline Patient \# & $\begin{array}{c}\text { Age at } \\
\text { Surgery }\end{array}$ & Sex & $\begin{array}{c}\text { Date of } \\
\text { Surgery }\end{array}$ & $\begin{array}{c}\text { Days between } \\
\text { Surgery and } \\
\text { Symptom Onset } \\
\text { (Hazard Period/HP) }\end{array}$ & $\begin{array}{c}\text { Days between } \\
\text { Surgery and } \\
\text { Diagnosis of } \\
\text { Enterococcus faecalis } \\
\text { Bacteremia }\end{array}$ \\
\hline 01 & 20 & M & $18 / 01 / 2013$ & 2 & 104 \\
02 & 54 & M & $23 / 01 / 2013$ & 33 & 115 \\
03 & 17 & M & $04 / 04 / 2013$ & 72 & 79 \\
04 & 46 & F & $19 / 04 / 2013$ & 30 & 48 \\
05 & 54 & M & $03 / 06 / 2013$ & 73 & 149 \\
06 & 18 & F & $08 / 07 / 2013$ & 14 & 59 \\
07 & 77 & M & $27 / 08 / 2013$ & 10 & 35 \\
08 & 65 & F & $25 / 09 / 2013$ & 1 & 30 \\
09 & 16 & M & $07 / 05 / 2014$ & 54 & 75 \\
10 & 29 & M & $20 / 06 / 2014$ & 13 & 110 \\
11 & 23 & M & $27 / 06 / 2014$ & 32 & 90 \\
12 & 21 & M & $18 / 07 / 2014$ & Unknown & 128 \\
13 & 69 & F & $31 / 07 / 2014$ & 20 & 77 \\
14 & 49 & M & $21 / 08 / 2014$ & 8 & \\
\hline
\end{tabular}

\subsection{Causation Analysis}

The case was analyzed using the INFERENCE framework. INFERENCE consists of two main parts, i.e., (1) the definition of the relevant medicolegal question and terms and (2) a three-step process of causal analysis based on the Hill criteria (plausibility, temporality, and alternative explanations), which is designed to quantify the probability of causation.

In Mrs. D's legal action, the use of INFERENCE was necessitated by the defendant's theory that it was only possible that her BE was caused by Dr. X's negligence. Therefore, it was necessary to compare/quantify how much more probable it was that Mrs. D acquired her BE due to the dental procedure performed by Dr. X, versus her chance of contracting the infection if she had not had the procedure.

\section{Results}

3.1. Steps of the INFERENCE Approach, Applied to the Specific Facts of Mrs. D's BE Infection 3.1.1. Step 1-Define the Medicolegal Causation Question and Determine Whether INFERENCE Is Required

The causal question was formulated based on the competing causal theories/legal hypotheses of the opposing parties. This causal question was in the form of comparison or ratio of probabilities based on counterfactual reasoning, as follows: "What was the risk of $\mathrm{BE}$ to Mrs. D as a patient of Dr. X during the timeframe of interest compared to her risk of BE during the same timeframe had she not been a patient of Dr. X?" The complexity of the causal question and, in particular, the need for a quantified answer ruled out the use of intuition alone as a sufficient approach. Hence, the analysis proceeded to the next step.

\subsubsection{Step 2-Evaluate the Relevant Factual Basis for the INFERENCE Causal Approach}

The available evidence relevant to the causal question was assessed in this step, including the demographic, medical, and historical information. At 69 years of age, Mrs. D belonged to the age group with the highest all-cause risk of infective endocarditis [18-20]. The timing of her symptoms and diagnoses were detailed and confirmed from her medical records. Although it was not until more than four months after her dental surgery that Mrs. D was diagnosed with BE, she began experiencing signs and symptoms consistent with symptoms of bacteremia after approximately 20 days post-procedure, including fever, flu-like symptoms, radiating pain, and dizziness [21]. Mrs. D had no known predisposing factors to BE during this 20-day interval, e.g., intravenous drug use, congenital heart 
diseases, and chronic intravenous access. These relevant demographic and medical data, the issue of appropriate timing and sequence, and the absence of possible alternative explanations were indicative of causation according to Hill's criteria [22].

\subsubsection{Step 3-Identify the Medicolegal Causation Elements for Calculation of the PC}

The medicolegal causation question was then broken down into the elements required to calculate the probability of causation $[17,23]$ :

- The condition of interest: enterococcal BE.

- The alleged primary harmful exposure resulting in the condition of interest: the dental surgical procedure provided by Dr. X, in which IPAC was allegedly violated.

- The hazard period: the time between the primary harmful exposure and first history of symptomatic manifestation of the condition of interest, i.e., 20 days.

- Potential competing causes: enterococcal BE risk resulting from all known and unknown causes, aside from the primary harmful exposure, occurring during the 20-day hazard period (see Table 2). Because there are no competing events or predictive factors that put Mrs. D at greater risk than the average woman in her age group, her risk is equal to the hazard-period-adjusted background rate of BE relevant to the population group of females aged $\geq 60$ years.

\subsubsection{Step 4-Calculate the Comparative Risk Ratio and Probability of Causation}

In this step, the primary harmful exposure and plausible competing cause risks were assessed, quantified, and compared as a ratio. First, the plausibility of the suspected primary harmful exposure and competing risks were assessed as causes of the condition of interest. Then, the risk of the condition of interest given the primary harmful exposure was compared with the risk of the condition of interest from the alternative causes as a ratio (i.e., comparative risk ratio or CRR). These elements of the final step, as applied to the facts of Mrs. B's infection, were as follows:

Plausibility assessment: The available facts indicated that the recent invasive dental procedure, advancing age, and possible associated degenerative valvular disease were well established as plausible causes of Mrs. D's BE [9,11,12,19,20].

Comparative risk ratio calculation: To proceed to this final step, the numerator (risk due to the primary harmful exposure) and denominator (risk due to alternative cause) values of the comparative risk ratio needed to first be estimated. The risk of the condition of interest given the primary harmful exposure is the number of people who contracted BE among Dr. X's patients during the timeframe of interest, which was $0.37 \%$. This figure was calculated from the information that 14 cases of $\mathrm{BE}$ were diagnosed among 3756 patients who attended the practice in 2013-2014. For ease of communication to laypersons, the frequency can also be described as 1 case in 268 patients.

The CRR denominator value is an estimate of the hazard-period-adjusted risk of the condition of interest due to all other plausible alternative causes. For Mrs. D's case, this value was estimated from the annual risk of enterococcal endocarditis for women in her age group (i.e., $\geq 60$ years) living in the U.S. The U.S. national hospital data indicate that there were 1255 cases of enterococcal endocarditis in women $\geq 60$ years old during 2013-2014, among a total population of approximately 32,000,000 women aged 60 years and above $[24,25]$. This frequency equates to an annual incidence of $0.00196 \%$, or a base rate of 1 case per 51,020 per year. This annual base rate risk was adjusted to the hazard period to arrive at a 20-day cumulative risk by dividing the annual risk by 18.25 (as there are 18.25 20-day periods in a year), resulting in a final estimate of the risk that Mrs. D would have acquired BE during the 20-day hazard period in the absence of the primary harmful exposure of 1 in 931,115.

The comparative risk ratio ( $C R R)$ was thus calculated as follows:

$$
C R R=\frac{1 \text { in } 268}{1 \text { in } 931,115} 3474
$$


The comparative risk ratio indicates that Mrs. D's BE was approximately 3474 times more likely to be caused by her oral surgery than due to any known (and unknown) competing cause.

Probability of causation (PC) calculation: To allow for easier comparison to the standard of proof as required by the court, the comparative risk ratio was converted into a probability of causation using the following formula:

$$
\mathrm{PC}=\frac{(C R R-1)}{C R R} \times 100 \%=\frac{(3474-1)}{3474} \times 100 \% 99.9 \%
$$

The calculation shows a greater than $99.9 \%$ probability that Mrs. D's BE was causally related to the oral surgery at Dr. X's practice.

\subsection{Flowchart of the INFERENCE Process}

Flowchart (Figure 1) of the INFERENCE Process:

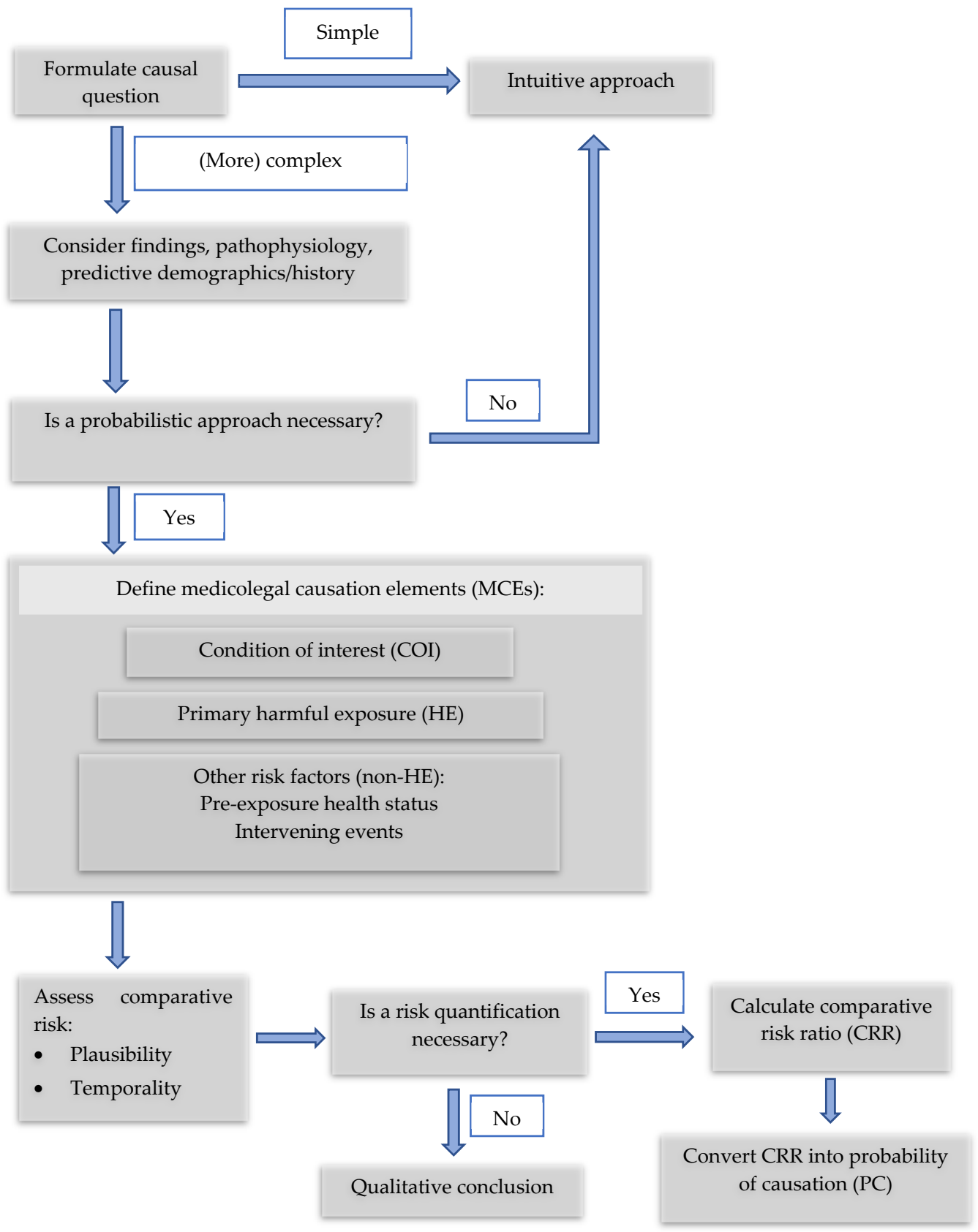

Figure 1. Flowchart of the INFERENCE approach [17]. 


\section{Discussion}

This paper aims to describe the step-by-step application of the INFERENCE approach [17] to a medical negligence case. The case described in this report is used as an example to quantify the probability that a case of BE was part of an outbreak related to a single clinic, as opposed to a sporadic and unrelated case.

Causality is an unobservable phenomenon and, thus, can only be inferred retrospectively via comparison of risks. This fact results in the inability to prove or demonstrate causation with direct evidence, unlike a clinical diagnosis [26]. Due to this reason, the defense could raise the theory that the plaintiff's infection was just as likely to have been a sporadic case of BE of unknown origin as a competing theory to the plaintiff's attribution of the $\mathrm{BE}$ to negligently delivered oral surgery care. While there is no way to know precisely where all of the infections occurred, the magnitude of increased risk to patients of Dr. $X$ cannot be explained by random accumulation of infections that are coincidental to the exposure at the practice.

The application of the INFERENCE approach provided a series of steps and instructions that resulted in quantification and comparison of the probabilities associated with the competing theories. One advantage of the approach was that the court was presented with a probability of causation that could be compared to the required standard of proof, i.e., that Mrs. D's BE was more likely related to the outbreak than not.

Without a quantified causation opinion, the court would have had to choose between well-qualified and persuasive experts from both sides, who both claim to have followed generally accepted scientific methods but still came to contradictory opinions regarding the most probable cause of Mrs. D's infection. The use of INFERENCE provides the court with a guide for the degree of weight that should be assigned to the defense's causation theory (i.e., $<0.1 \%$ ) in making determinations of liability, causation, and damages.

Legal standards and customary methods used for causal analysis may differ in various countries and jurisdictions. Thus, one of the reasons for the present study is to describe a method that is meant to be used universally, when appropriate. We have developed INFERENCE as a cognitive approach for the medicolegal/forensic medical practitioner that can be used in various settings, regardless of the legal system.

It is worth noting that the denominator value for the comparative risk ratio calculation (i.e., the base rate risk of $\mathrm{BE}$ due to causes other than the oral surgery exposure) was intentionally overestimated. Mrs. D had no risk factors for BE, and thus using the rate for the entire population likely underestimated the risk for the subpopulation with BE risk factors (e.g., artificial heart valves or intravenous drug use) and overestimated it for most of the population, who, like Mrs. D, have no BE risk factors. The choice to overestimate the base rate of $\mathrm{BE}$ and, thus, inflate the denominator to some degree was deemed appropriate based on a "safety analysis" approach that minimizes Type I (false positive) error risk at the expense of an increased Type II (false negative) error risk. Thus, to the degree that bias exists in the analysis, it favors the opposing (defense) rather than the retaining (plaintiff) party. The large comparative risk ratio value, however, made the issue moot.

\section{Conclusions}

The INFERENCE approach is a practical stepwise system for organizing evidence and quantifying causal probabilities when causation is disputed. Despite some increased complexity, a key advantage of an INFERENCE analysis is that it provides the court with an evidence-based, transparent, and reliable expert quantification of the probability of causation, as demonstrated in the above analysis.

Author Contributions: Conceptualization, P.D.I.M., M.P.Z., H. and M.D.F.; methodology, P.D.I.M., M.P.Z., H. and M.D.F.; investigation, P.D.I.M. and M.D.F.; resources, P.D.I.M. and M.D.F.; writingoriginal draft preparation, P.D.I.M. and M.D.F.; writing-review and editing, M.P.Z. and H.; visualization, P.D.I.M.; supervision, M.P.Z.; project administration, P.D.I.M.; funding acquisition, P.D.I.M. All authors have read and agreed to the published version of the manuscript. 
Funding: This work was supported by the Indonesia Endowment Fund for Education (LPDP) scholarship body as part of a Doctoral Scholarship Program.

Institutional Review Board Statement: Not applicable.

Informed Consent Statement: Not applicable.

Data Availability Statement: Not applicable.

Conflicts of Interest: All authors provide medicolegal consultation services.

\section{References}

1. Madea, B. History of forensic medicine-A brief introduction. In History of Forensic Medicine; Madea, B., Ed.; Lehmanns Media, GmbH: Berlin, Germany, 2017; pp. 3-27.

2. Pinheiro, J. Introduction to forensic medicine and pathology. In Forensic Anthropology and Medicine: Complementary Sciences from Recovery to Cause of Death; Schmitt, A., Cunha, E., Pinheiro, J., Eds.; Humana Press Inc.: Totowa, NJ, USA, 2006 ; pp. 13-38.

3. Weiner-Lastinger, L.M.; Abner, S.; Edwards, J.R.; Kallen, A.J.; Karlsson, M.; Magill, S.S.; Pollock, D.; See, I.; Soe, M.M.; Walters, M.S.; et al. Antimicrobial-resistant pathogens associated with adult healthcare-associated infections: Summary of data reported to the National Healthcare Safety Network, 2015-2017. Infect. Control. Hosp. Epidemiol. 2020, 41, 1-18. [CrossRef] [PubMed]

4. Monteserin, N.; Larson, E. Temporal trends and risk factors for healthcare-associated vancomysin-resistant enterococci in adults. J. Hosp. Infect. 2016, 94, 236-241. [CrossRef] [PubMed]

5. Kohn, W.G.; Harte, J.A.; Malvitz, D.M.; Collins, A.S.; Cleveland, J.L.; Eklund, K.J. Guidelines for infection control in dental health care settings-2003. J. Am. Dent. Assoc. Am. Dent. Assoc. 2004, 135, 33-47. [CrossRef] [PubMed]

6. Centers for Disease Control and Prevention (CDC). Guidelines for Infection Control in Dental Health Care Settings-2003; MMWR; Centers for Disease Control and Prevention: Atlanta, GA, USA, 2003; Volume 52, pp. 1-61.

7. CDC. Summary of Infection Prevention Practices in Dental Settings-Basic Expectations; Centers for Disease Control and Prevention (CDC): Atlanta, GA, USA, 2016.

8. Lockhart, P.B.; Brennan, M.T.; Sasser, H.C.; Fox, P.C.; Paster, B.J.; Bahrani-Mougeot, F.K. Bacteremia associated with toothbrushing and dental extraction. Circulation 2008, 117, 3118-3125. [CrossRef] [PubMed]

9. Ito, H.O. Infective endocarditis and dental procedures: Evidence, pathogenesis, and prevention. J. Med. Investig. 2006, 53, 189-198. [CrossRef] [PubMed]

10. Maharaj, B.; Coovadia, Y.; Vayej, A.C. An investigation of the frequency of bacteraemia following dental extraction, tooth brushing and chewing. Cardiovasc. J. Afr. 2012, 23, 340-344. [CrossRef] [PubMed]

11. Vincent, L.L.; Otto, C.M. Infective Endocarditis: Update on Epidemiology, Outcomes, and Management. Curr. Cardiol. Rep. 2018, 20, 1-9. [CrossRef] [PubMed]

12. Castillo, J.C.; Anguita, M.P.; Torres, F.; Siles, J.R.; Mesa, D.; Vallés, F. Risk factors associated with endocarditis without underlying heart disease. Revista Espanola de Cardiologia 2002, 55, 304-307. [CrossRef]

13. Institute of Environmental Science \& Research. Guidelines for the Investigation and Control of Disease Outbreaks; Institute of Environmental Science \& Research Ltd.: Porirua, New Zealand, 2012.

14. Sood, G.; Perl, T.M. Outbreaks in health care settings. Infect. Dis. Clin. N. Am. 2016, 30, 661-687. [CrossRef] [PubMed]

15. Koehler, S.A.; Freeman, M.D. Forensic epidemiology: A method for investigating and quantifying specific causation. Forensic Sci. Med. Pathol. 2014, 10, 217-222. [CrossRef] [PubMed]

16. Ross, K.M.; Mehr, J.S.; Greeley, R.D.; Montoya, L.A.; Kulkarni, P.A.; Frontin, S.; Weigle, T.J.; Giles, H.; Montana, B.E. Outbreak of bacterial endocarditis associated with an oral surgery practice. J. Am. Dent. Assoc. 2018, 149, 191-201. [CrossRef] [PubMed]

17. Meilia, P.D.I.; Zeegers, M.P.; Herkutanto Freeman, M. Inference: An evidence-based approach for medicolegal causal analyses. Int. J. Environ. Res. Public Health 2020, 17, 8353. [CrossRef] [PubMed]

18. Yew, H.S.; Murdoch, D.R. Global trends in infective endocarditis epidemiology. Curr. Infect. Dis. Rep. 2012, 14, 367-372. [CrossRef] [PubMed]

19. Slipczuk, L.; Codolosa, J.N.; Davila, C.D.; Romero-Corral, A.; Yun, J.; Pressman, G.S.; Figueredo, V.M. Infective endocarditis epidemiology over five decades: A systematic review. PLoS ONE 2013, 8. [CrossRef] [PubMed]

20. Chirouze, C.; Athan, E.; Alla, F.; Chu, V.H.; Ralph Corey, G.; Selton-Suty, C.; Erpelding, M.-L.; Miro, J.M.; Olaison, L.; Hoen, B.; et al. Enterococcal endocarditis in the beginning of the 21st century: Analysis from the international collaboration on endocarditisprospective cohort study. Clin. Microbiol. Infect. Eur. Soc. Clin. Infect. Dis. 2013, 19, 1140-1147. [CrossRef] [PubMed]

21. Habib, G.; Lancellotti, P.; Antunes, M.J.; Bongiorni, M.G.; Casalta, J.P.; del Zotti, F.; Dulgheru, R.; El Khoury, G.; Erba, P.A.; Iung, B.; et al. 2015 ESC Guidelines for the management of infective endocarditis. Eur. Heart J. 2015, 36, 3075-3128. [CrossRef] [PubMed]

22. Höfler, M. The Bradford Hill considerations on causality: A counterfactual perspective. Emerg. Themes Epidemiol. 2005, 2, 1-9. [CrossRef] [PubMed]

23. Dawid, A.P.; Musio, M.; Murtas, R. The probability of causation. Law Probab. Risk 2017, 16, 163-179. [CrossRef] 
24. United States Census Bureau. Explore Census Data. Available online: https://data.census.gov/cedsci/?q=UnitedStates (accessed on 20 December 2020).

25. Healthcare Cost and Utilization Project (HCUP). Overview of the National (Nationwide) Inpatient Sample (NIS). HCUP-US NIS; 2020. Available online: https:/ / www.hcup-us.ahrq.gov/nisoverview.jsp (accessed on 20 December 2020).

26. Honore, A. Principles and Values Underlying the Concept of Causation in Law. In Causation in Law and Medicine; Mendelson, D., Freckelton, I.R., Eds.; Routledge: New York, NY, USA, 2016; pp. 3-13. 